\title{
PEMBIASAAN MENGGOSOK GIGI UNTUK MENJAGA KESEHATAN GIGI DAN MULUT
}

\author{
Fitria Arumsari \\ Email: arummouri@gmail.com \\ TKK Sinar Bangsa Nikisie, Kab. Ngada, NTT
}

\begin{abstract}
Abstrak
Berawal dari banyaknya anak yang tidak gosok gigi saat pergi ke sekolah yang dikarenakan kurangnya kesadaran orang tua tentang pentingnya menjaga kesehatan gigi dan mulut anak dan juga kesibukan orang tua dalam bekerja, maka guru membuat pembiasaan yaitu menggosok gigi di sekolah. Gosok gigi dilakukan setiap hari sebelum proses belajar mengajar berlangsung dan diikuti oleh seluruh siswa TK dari kelompok A dan B. Dalam pelaksanaannya guru menggunakan metode demonstrasi. Guru memberi contoh cara menggosok gigi yang benar dan anak mengikuti. Hasil dari kegiatan ini diharapkan anak memahami pentingnya menjaga kesehatan gigi dan mulut. Selain itu anak menjadi rajin menggosok gigi di sekolah maupun di rumah, sehingga anak dapat memiliki gigi yang sehat.
\end{abstract}

Kata kunci: Pembiasaan, gosok gigi, anak TK

\begin{abstract}
The high number of students that does not brush their teeth before going to school because of the low awareness from the parents regarding the importance of maintaining teeth and oral hygiene and also the parents' working activities forced the teachers to decide brushing teeth at school as a school routine. Brushing teeth is done every day before starting the learning activities and is joined by all of the students from group $A$ and $B$.

Teachers used demonstration method in carrying out the program. Teachers gave example on how to brush teeth correctly and students followed. It is expected from the program that students understand the importance of maintaining teeth and oral hygiene. Apart from that, students are expected to get accustomed to brush their teeth frequently either at school or at home thus they have healthy teeth.
\end{abstract}

Keywords: habit, brush teeth, kindergarten students

\section{Pendahuluan}

TKK Sinar Bangsa Nikisie terletak di Dusun Doka, Desa Naruwolo I, Kecamatan Jerebuu, Kabupaten Ngada, Nusa Tenggara Timur. Desa ini terletak di kaki gunung Inerie yang merupakan gunung tertinggi di NTT. Pendirian sekolah diawali dengan tidak adanya instansi pendidikan untuk anak usia TK yaitu $4-6$ tahun. Sekolah berdiri pada tahun 2007 dengan dana dari PNPM. Sekolah ini mempunyai luas tanah 1.755 $\mathrm{m}^{2}$. Pelaksanaan belajar mengajar di sekolah ini berlangsung pagi hari.
Pada awalnya TKK Sinar Bangsa Nikisie merupakan TK Satap (Satu Atap) dengan SD Inpres Nikisie. Namun, atas instruksi pemerintah daerah pada Maret 2015 sekolah TK ini memisahkan diri dan berdiri sendiri. Saat ini TKK Sinar Bangsa Nikisie di pimpin oleh Bernadetha Mesi, $\mathrm{S}$. Si yang menjabat sebagai kepala sekolah. TKK Sinar Bangsa Nikisie memilikki 2 ruang kelas (kelompok A dan B), satu ruang guru dan kepala sekolah, 2 ruang toilet, satu halaman sekolah dan satu taman bermain. Total anak yang terdaftar di sekolah ini adalah 30 orang, terdiri dari 13 anak kelompok A dan 17 anak 
kelompok B. Guru yang mengajar di sekolah ini berjumlah 2 orang, yang semuanya merupakan guru honorer dan dibiayai oleh BOSDIK dan juga komite sekolah. Ibu Kristina Bate mengajar di kelompok A dan Ibu Bernadetha Mesi, S. Si mengajar di kelompok B.

Mata pencaharian orang tua siswa umumnya adalah petani. Adapun hasil dari pertanian di daerah ini adalah jagung, kemiri, merica, kakao, cengkih, kelapa, dsb. Selain dibidang pertanian, banyak dari orang tua yang juga memelihara hewan ternak diantaranya adalah kerbau, sapi, kuda, kambing, anjing, babi, ayam, dsb.

Kesibukan orang tua dan kesadaran akan kesehatan yang masih rendah membuat anak-anak datang ke sekolah dengan pakaian yang kumal, rambut acak-acakan dan ingus di hidung. Mereka bangun tidur langsung menuju ke sekolah tanpa ganti pakaian, cuci muka, apalagi mandi dan gosok gigi. Di TKK Sinar Bangsa Nikisie, hampir semua anak belum gosok gigi saat akan berangkat ke sekolah. Itulah mengapa dapat dikatakan bahwa mereka kurang sadar akan pentingnya kesehatan terutama gigi dan mulut.

Kerusakan gigi banyak dialami anakanak, seperti gigi berlubang. Penyebabnya konsumsi gula berlebih, perawatan gigi yang sering kali terabaikan, dan hal utama seperti gosok gigi jarang bahkan tidak dilakukan baik di rumah maupun di sekolah. Terdapat kebiasaan unik dari warga disini yaitu "ngeu" atau makan sirih pinang. Kebiasaan ini dilakukan mulai dari orang tua hingga anakanak, termasuk anak beberapa anak TK. Akibatnya gigi menjadi kuning bahkan menghitam.

Kesehatan gigi dan mulut anak sangat penting dilakukan. Anak pada umumnya belum mengerti pentingnya menjaga kesehatan gigi dan mulut. Disitulah peran orang tua dan guru sangat dibutuhkan untuk menamkan gosok gigi pada anak sejak usia dini, agar menjadi kebiasaan yang terbawa sampai anak dewasa.

\section{Kesehatan Gigi dan Mulut}

Gigi dan mulut merupakan bagian penting yang harus dijaga kebersihannya. Menurut WHO dalam Andreas Winardi
(2012), kebersihan atau kesehatan gigi dan mulut adalah praktek melakukan penjagaan kebersihan dan kesehatan mulut dengan cara menyikat dan melakukan flossing untuk mencegah timbulnya problem pada gigi. Perawatan gigi sejak dini sangat penting dilakukan karena banyak anak menderita karies atau lubang pada gigi.

Berikut ini merupakan permasalahan kesehatan gigi dan mulut anak yang banyak dialami sehari-hari (Pilihan Ibu, 2012):

\section{a. Tumbuh Gigi}

Tumbuh gigi dimulai saat anak masih bayi dan mulai mengenal makanan semipadat. Makanan semipadat dapat membantu merangsang tumbuhnya gigi.

b. Gigi Copot

Gigi copot adalah fase dalam pertumbuhan gigi. Fase ini merupakan persiapan bagi gigi baru (gigi sekunder) yang permanen untuk digunakan hingga mereka dewasa.

\section{c. Kerusakan Gigi}

Kerusakan gigi banyak terjadi pada anak-anak seperti, susunan gigi yang tidak rata, gigi berlubang, karies, dan warna gigi yang tidak putih. Hal ini disebabkan oleh penggunaan botol susu dan empeng, konsumsi gula berlebih, kurangnya perawatan gigi, hingga penggunaan obat tertentu.

\section{d. Sakit Gigi}

Sakit gigi adalah imbas dari kerusakan gigi. Sakit gigi pada anak-anak yang paling banyak terjadi adalah gigi berlubang. Di sini terjadi kontak makanan dengan saraf gigi yang terekspos ke luar akibat lapisan dentin gigi yang rusak.

\section{e. Perawatan Gigi}

Perawatan gigi seperti menggosok gigi dan pemeriksaan ke dokter seringkali terabaikan. Banyak orang tua yang menganggap pemeriksaan gigi kurang begitu penting.

\section{Penyebab Kerusakan Gigi}

Kerusakan gigi banyak terjadi pada anak-anak, menurut Lisa Fals (2015) hal 
tersebut disebabkan karena beberapa faktor, antara lain:

a. Malas untuk menyikat gigi. Anakanak memang belum terbiasa untuk sikat gigi, tapi bukan berarti membiarkan gigi mereka tidak dibersihkan. Orang tua harus mengajarkan bagaimana cara menyikat gigi anak dengan benar, membiasakan, dan memberi pengertian akan dampak buruk jika tidak menyikat gigi.

b. Makan makanan manis dan lengket yang berlebihan. Mungkin ini bisa menjadi penyebab utama gigi berlubang pada anak-anak, karena mereka memang suka dengan makanan manis. Itu dikarenakan makanan manis merupakan kesukaan kuman-kuman yang berada di mulut.

c. Tidur setelah makan. Ini tidak akan menjadi masalah jika sebelum tidur anak-anak menyikat giginya, tetapi jika tidak maka akan menjadi salah satu penyebab gigi berlubang. Setelah makan kondisi mulut akan bersifat asam, sehingga membutuhkan air liur yang banyak untuk menetralisir kondisi asam tersebut. Pada saat tidur, air liur yang diproduksi oleh mulut tidak terlalu banyak.

d. Waktu menyikat gigi yang tidak tepat. Kebiasaan kita adalah menyikat gigi saat mandi, baik itu mandi pagi atau sore. Yang paling tepat ialah menyikat gigi setelah makan.

e. Sering mimun yang bersoda. Soda memiliki tingkat keasaman yang tinggi, yang menyebabkan terjadinya demineralisasi pada gigi, yang selanjutnya akan membentuk lubang pada gigi.

\section{Cara Merawat Kesehatan Gigi dan Mulut Rumah Sakit MH Thamrin} Purwakarta (2016) menuliskan bahwa ada beberapa cara untuk merawat kesehatan gigi dan mulut anak, yaitu:

a. Sikat Gigi yang Tepat
Gunakan sikat gigi anak yang memiliki bulu sikat yang lembut. Hal ini untuk melindungi gusi dan berfokus pada daerah-daerah kecil sehingga mereka dapat membersihkan dengan benar. Selain itu karakter kartun yang lucu pada sikat gigi dapat membuat anak menyukai menyikat gigi.

b. Cara Menyikat

Pastikan untuk mengajari anak anda cara menyikat yang benar. Gerakan perlahan dan memutar pada seluruh bagian permukaan gigi. Jangan terlalu keras dalam menyikat, karena dapat melukai gusi anak yang masih lemah.

c. Pasta Gigi

Gunakan pasta gigi khusus untuk anak yang memiliki rasa yang mereka sukai. Biarkan mereka memilih sendiri rasa yang menjadi favorit mereka seperti coklat, es krim, strawberry, dan buah lainnya. Rasa pasta gigi yang yang enak baik dalam memotivasi anak untuk terus menyikat giginya.

\section{d. Kunjungi Dokter Gigi}

Kunjungi dokter gigi minimal 6 bulan sekali untuk memastikan gigi anak tetap sehat dan kuat. Hal ini sangat penting untuk tetap memastikan kesehatan mulut dan gigi anak bila terdapat masalah kesehatan mulut dan gigi.

Sedangkan menurut Ibar Maulana (2011) ada beberapa cara untuk merawat atau mencegah kerusakan gigi pada anak, yaitu:

a. Membersihkan gigi anak sejak gigi pertama tumbuh, biasanya pada umur 6 bulan. Pembersihan dilakukan setiap malam sebelum tidur.

b. Pemeriksaan rutin ke dokter gigi, setidaknya 6 bulan sekali. 
Pemeriksaan rutin membantu menjaga kesehatan mulut anak. Biarkan anak menjadi akrab dengan dokter gigi dan jangan menanamkan rasa takut.

c. Pastikan anak menyikat gigi secara teratur dua kali sehari. Mulailah mengajarkan menyikat gigi ketika anak sudah cukup besar, biasanya pada usia 2 tahun. Lebih baik dari orang tua dalam mencontohkan cara menyikat gigi kepada anak.

d. Siapkan makanan bergizi seperti buah-buahan, sayuran dan keju yang mengandung banyak kalsium dan rendah asam dan gula. Hindari makanan manis yang lengket.

e. Jangan memasukkan sendok dan garpu ke mulut anak jika sendoh tersebut sudah pakai, agar bakteri penyebab kerusakan gigi tidak menular.

f. Mengganti sikat gigi setiap tiga bulan sekali. Pilih sikat gigi yang lembut khusus untuk anak-anak.

g. Cobalah untuk tidak menggunakan pasta gigi fluoride ketika anak masih kecil karena mereka mungkin menelan pasta gigi itu tanpa sengaja.

h. Ganti gula dengan madu karena madu tidak kariogenik (menyebabkan karies gigi).

i. Tidak memberikan susu, jus atau minuman manis saat anak akan tidur. Cairan itu akan terperangkap di bawah bibir atas anak dan dapat menyebabkan gigi depan atas mereka membusuk.

Membiasakan menyikat gigi dua kali sehari dan selalu menjaga kebersihan mulut merupakan hal yang bermanfaat bagi anak. Selain itu mengurangi makanan yang terlalu banyak gula dan manis juga dapat membantu menjaga kesehatan gigi dan mulut.

\section{Cara Menyikat Gigi dengan Baik dan Benar}

Gosok gigi adalah cara paling mudah untuk menjaga kesehatan gigi dan mulut. Akan tetapi banyak orang yang menyepelekan pentingnya gosok gigi. Terdapat cara-cara untuk menggosok gigi dengan baik dan benar (Jennifer Lucinda, 2013):

a. Ambil sikat dan pasta gigi, peganglah sikat gigi dengan cara sendiri (yang penting nyaman untuk dipegang), oleskan pasta gigi di sikat gigi yang sudah dipegang.

b. Sikat gigi (gigi depan dengan cara menjalankan sikat gigi pelan-pelan dan naik turun. Kenapa harus pelanpelan karena biasanya orang yang menyikat gigi secara kasar, akan mengakibatkan gusi lecet dan berdarah.

c. Langkah selanjutnya gosok bagian gigi sebalah kanan dan kiri. Cara pengaplikasian hampir sama dengan menyikat gigi depan, yaitu gosok perlahan dengan irama naik turun. Jika susah mengosok naik turun bisa menggosok biasa namun dengan durasi lebih lama, karena mengosok dengan cara naik turun walaupun pelan-pelan akan lebih cepat menghilangkan sisa makanan yang tertempel.

d. Setelah selesai menggosok area gigi bagian kanan, kiri dan depan, maka langkah selanjutnya adalah membersihkan/ menyikat gigi bagian dalam (gigi geraham). Usahakan sikat dengan cara pelan-pelan namun kotoran tak ada yang tertinggal karena biasanya plak kuning terjadi di area ini jika gosok giginya tidak bersih. Caranya, gunakanan ujung bulu sikat untuk menjangkau area gigi geraham dengan sedikit tekanan sampai ujung sikat sedikit melungkung. 
e. Langkah terakhir gosok gigi dalam (gigi tengah) dengan cara menegakan lurus sikat gigi, lalu sikat gerakkan sikat keatas kebawah.

\section{Implementasi}

Kurangnya pengetahuan tentang pentingnya menjaga kesehatan gigi dan mulut dan kesibukan orang tua siswa dalam bekerja, membuat guru harus memberikan pembiasaan yang baik kepada anak melalui gosok gigi di sekolah. Yaitu mengajarkan bagaimana cara menyikat gigi dengan benar, membiasakan, dan memberi pengertian akan dampak buruk jika tidak menyikat gigi (Lisa Fals, 2015). Hal ini bertujuan agar anak mengetahui cara menggosok gigi yang benar dan mulai merawat kesehatan gigi mereka sejak dini.

Tidak adanya fasilitas gosok gigi di sekolah yaitu sikat dan pasta gigi, anakanak diminta untuk membawa sikat gigi dari rumah dan guru menyediakan pasta gigi. Akan tetapi banyak anak yang membawa sikat gigi bekas bahkan ada juga yang membawa sikat gigi milik mama atau bapak mereka. Guru menuliskan nama pada sikat gigi sesuai nama anak agar tidak tertukar dengan milik anak lain. Pasta gigi yang digunakan adalah pasta gigi untuk anak dengan rasa jeruk, stroberi dan coklat. Namun, belum semua anak dapat mengikuti kegiatan gosok gigi ini karena beberapa dari mereka ada yang tidak membawa sikat gigi.

Anak-anak diminta berbaris di depan kelas dengan memegang sikat gigi masingmasing. Jarak antara anak yang satu dengan yang lain $\pm 40 \mathrm{~cm}$, agar tidak bersenggolan satu dengan yang lain. Guru memberikan air di gelas-gelas plastik kepada anak untuk berkumur. Setelah itu memberikan pasta gigi secara bergiliran. Banyak dari anak yang mencoba untuk menjilat pasta gigi, dan mereka terkejut karena rasanya yang enak, rasa buah dan coklat. Ada juga yang menelan pasta gigi karena mereka pikir itu adalah permen.
Sehingga guru mengingatkan bahwa itu adalah pasta gigi bukan makanan dan tidak bisa dimakan, hanya digunakan untuk membersihkan gigi.

Anak mengikuti arahan guru tentang tata cara menggosok gigi yang benar. Bahwa menggosok gigi itu harus pelanpelan agar tidak terluka dan mengeluarkan darah. Banyak anak yang belum bisa mengikuti arahan guru, sehingga guru harus membimbing satu persatu anak agar mereka paham tata cara menggosok gigi yang benar. Selanjutnya anak diminta membedakan bagaimana rasanya sebelum dan sesudah menggosok gigi. Kegiatan gosok gigi ini akan dilaksanakan setiap pagi sebelum proses belajar mengajar dimulai dan diikuti oleh seluruh anak kelompok A dan B, agar anak-anak dapat menerapkan pembiasaan gosok gigi baik di sekolah maupun di rumah.

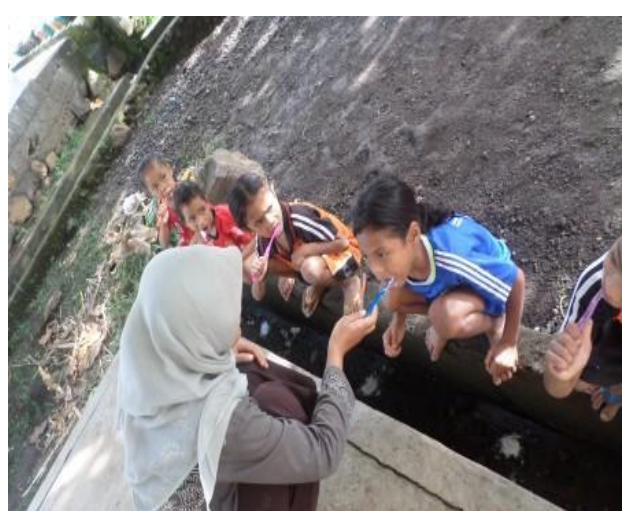

Gambar 1.

Foto saat guru membimbing anak dalam menggosok gigi yang benar.

Keterbatasan fasilitas tidak menjadi masalah. Harapannya agar anak mengerti pentingya merawat kesehatan dan kebersihan gigi dan mulut dengan menggosok gigi. Sehingga mereka akan memiliki gigi yang sehat dan kuat.

\section{Kesimpulan}

Dari pengamatan yang dilakukan di TKK Sinar Bangsa Nikisie, guru menemukan permasalahan bahwa anak kurang memahami pentingnya menjaga kesehatan gigi dan mulut. Hal itu 
disebabkan karena orang tua yang sibuk dengan pekerjaan sehingga kurang memperhatikan kesehatan gigi dan mulut anak.

Oleh karena itu, guru harus memberikan peran di lingkungan sekolah agar anak mulai mengenal kesehatan gigi dan mulut, yaitu dengan cara menggosok gigi. Guru menjelaskan mengapa kita perlu menjaga kesehatan gigi, apa akibatnya jika gigi tidak pernah dibersihkan, dan bagaimana cara menggosok gigi dengan baik dan benar.

Selain menggosok gigi, menjaga kesehatan gigi dan mulut anak juga dapat dilakukan dengan membatasi makanan yang banyak mengandung gula dan rutin memeriksakan gigi ke dokter. Memiliki gigi yang sehat dapat membantu anak menikmati makanan yang dimakan, berbeda jika gigi sakit. Sehingga orang tua maupun guru harus memberikan perhatian khusus dalam menjaga kesehatan gigi dan mulut anak.

\section{Daftar Pustaka}

Andreas Winardhi. 2012. Kesehatan Gigi dan Mulut. Di unduh di http://andreaswinardhi.blogspot. co.id /2012/10/kesehatan-gigi-danmulut.html pada tanggal 21 Maret 2016

Ibar Maulana. 2011. Mencegah Kerusakan Gigi pada Anak. Di unduh di http://ibarmaulana.blogspot.co.id/2 011/01/caratips-mencegahkerusakan-gigi-pada.html pada

Jennifer Lucinda. 2013. Cara Menggosok Gigi yang Benar. Di unduh di http://trik-tipssehat.blogspot.co.id/2013/07/caramenggosok-gigi.html pada tanggal 21 Maret 2016
Lisa Fals. 2015. Gigi Anak Rusak, Keropos, Berlubang, Apa Penyebabnya?. Di unduh di http://sakitgi2.blogspot.com/2015/0 6/gigi-anak-rusak-keroposberlubang-apa-penyebabnya.html pada tanggal 21 Maret 2016

RS. Thamrin Purwakarta. Perawatan Kesehatan Gigi dan Mulut Anak. Di unduh di http://thamrinhospitalpurwakarta.co m/index.php/new/346-kesehatangigi-anak pada tanggal 21 Maret 2016

Pilihan Ibu. 2012. Kesehatan Gigi dan Mulut Anak serta Permasalahannya. Di unduh di http://artikeltentangkesehatan.com/ kesehatan-gigi-dan-mulut-anakserta-permasalahannya.html pada tanggal 21 Maret 2016 